\title{
shannon entropy
}

\begin{tabular}{lccc} 
Predictors & Estimates & $C I$ & $p$ \\
\hline (Intercept) & 1.27 & $1.03-1.51$ & $<\mathbf{0 . 0 0 1}$ \\
evivo_ever2 [yes] & -0.37 & $-0.63--0.10$ & $\mathbf{0 . 0 0 9}$ \\
DOL & 0.02 & $0.01-0.02$ & $<\mathbf{0 . 0 0 1}$ \\
Validated_Cluster_group & 0.16 & $-0.09-0.42$ & 0.207 \\
[Escherichia] & & & \\
Validated_Cluster_group & -0.29 & $-0.48--0.10$ & $\mathbf{0 . 0 0 4}$ \\
[Staphylococcus_epidermidis] & & & \\
Random Effects & & & \\
$\sigma^{2}$ & & & \\
$\tau_{\text {O0 Subject.ID }}$ & 0.21 & & \\
ICC & 0.20 & & \\
$\mathrm{~N}_{\text {Subject.ID }}$ & 0.48 & & \\
\hline${ }^{\text {Observations }}$ & 76 & & \\
\hline
\end{tabular}

Observations

292

Marginal $\mathrm{R}^{2}$ / Conditional $\mathrm{R}^{2} \quad 0.302$ / 0.640 